\title{
"Internet +" Configuration Taxi Resource Era \\ $\mathrm{Li} \mathrm{Yi}{ }^{1 *}$, Huang $\mathrm{Fei}^{2}$
}

${ }^{1}$ Sichuan Minzu College,No. 4, Wenhua Road, Guzan Town, Kangding , Sichuan ,China 626001

${ }^{2}$ Sichuan University Jinjiang College,No. 1, Jinjiang Avenue, Pengshan District, Meishan, Sichuan, China 620860

DOI: $10.36347 /$ sjpms.2022.v09i01.002

| Received: 16.12.2021 | Accepted: 20.01.2022 | Published: 24.01.2022

*Corresponding author: $\mathrm{Li} \mathrm{Yi}$

Sichuan Minzu College,No. 4, Wenhua Road, Guzan Town, Kangding, Sichuan ,China 626001

Abstract

This paper mainly studies the problem of the difficulty of taking a taxi, first of all, the degree of matching supply and demand is affected by taxis and passengers, so the indicators can be established from both drivers and passengers. The indicators we established are taxi idling rate, people ownership, passenger waiting time. Then, we take the maximum matching number between driver and passenger and the minimum total waiting time of passengers as the objective function to establish the maximum matching model between passenger and driver. The case analysis shows that this method can achieve better utilization of taxi resources and has strong operability.

Keywords: Resource allocation; matching supply and demand; Maximum matching model; multi-objective optimization model.

Copyright (C) 2022 The Author(s): This is an open-access article distributed under the terms of the Creative Commons Attribution 4.0 International License (CC BY-NC 4.0) which permits unrestricted use, distribution, and reproduction in any medium for non-commercial use provided the original author and source are credited.

\section{INTRODUCTION}

As the "Internet + " era comes by, many Companies has launched taxi Software. But it is also difficult to configure a reasonable arrangement taxi Resources. In order to effectively solve the residents, travel difficult problem, so the research of taxis' allocation resources in the Internet age has great significance [1].

At different times, different places, The demand for taxis is different, Peak hours, demand for business-intensive areas people Taxis large, In order to solve internal and external conflicts of the taxi industry, Design reasonable taxi resource allocation scheme, The maximum to meet people's travel needs, Maximize the benefits both sides, reasonable arrangements for taxi allocation of resources, Not only can the full and effective use of resources, but also promote the development of the transport sector, and therefore have great significance [2].

\section{MODEL BUILDING}

Through analysis, appear irrational allocation of resources is affected by the taxi drivers and pedestrians in two ways [3]. Passengers wait for a long time without a taxi, the driver cannot find nearby passengers. Therefore, the establishment of indicators from taxi drivers and pedestrians on both sides, according to principles of constructing indicators, load rate indicators finalized, people ownership, passenger waiting time. Finally, according to indicators established computational analysis obtained at different times, in different locations of taxi resources' supply and demand match " degree.

\subsection{To determine the indicators 2.1.1 Index 1: taxi-no load rate}

Taxi no-load rate represents the percentage of passenger traffic mileage in the entire operation of carrying traffic [4]. From the taxi driver's point of view, the higher the no load rate, indicating that fewer drivers to load passengers, so will damage the interests of drivers. From the passenger's point of view, the lower the load, there will be "taxi difficult", "rejection" problem, so "matching supply and demand" and taxiload rate are related. research finding, No-load rate of 0.3 to 0.4 is optimal interval taxi service levels. If the load is higher than 0.4 , the utilization efficiency of the taxi will be significantly reduced, no-load rate is less than 0.3 , a taxi passenger waiting time will rise, cannot meet the needs of residents' travel [5], the definition of the formula: 
$k=1-\frac{L}{T V_{n}}$

$L=\frac{W_{1}}{S_{1}}+\frac{W_{2}}{S_{2}}$

$S=\frac{k_{1}+2 k_{2}+3 k_{3}+4 k_{4}}{k_{1}+k_{2}+k_{3}+k_{4}}$

$W_{1}=R_{1} A_{1} P_{1} D_{1}$

$W_{2}=R_{2} A_{2} P_{2} D_{2}$

In the above formula, $k$ represents load rate, $L$ represents the total effective downtown taxi mileage; $W_{1}$

Resident bear population represents city center taxi trip turnover, ${ }^{W_{2}}$ represents the central area of the city Taxi bear migrants traveling turnover; ${ }^{S_{1}}$ represents an average effective number of passenger trips when the central area of the city residents to take a taxi (person). $S_{2}$ Represents the central area of the city floating population average effective number of passenger trips taxis (person); $T$ represents an average operating time of taxi one day $(h) . V$ represents the average operating speed taxi $(\mathrm{km} / \mathrm{h}) ; R_{1}$ Represents the total number of residents of the city center area; $R_{2}$ represents the total number of floating population urban centers; ${ }^{A_{1}}$ represents the number of urban residents in the central area of travel per day on average; floating population in urban centers represent the number of trips per person per day; $P_{1}$ represents the proportion of taxi travel urban travel mode is selected; $P_{2}$ represents choose to travel by taxi to the proportion of migrants in travel mode; $D_{1}$ represents an average distance of city residents travel by taxi ways $(\mathrm{km}) ; D_{2}$ represents the average distance of the floating population in taxi mode of travel $(\mathrm{km})$.

\subsubsection{Index 2: Ten thousand people ownership}

People have a volume represents the number of taxis per 10,000 have, From the passenger's point of view, the more the number of taxis, taxi difficult probability is smaller, so it can be determined that the index, which is defined formula

$N=\frac{n_{c}}{n_{p}}$

In this formula, $n_{c}$ represents the total number

\subsubsection{Index 3: Passengers waiting time}

Passengers' waiting time can also reflect the degree of "supply and demand matching". When drivers refuse to take passengers and there is no taxi near passengers, passengers' waiting time will become longer, indicating that local demand may exceed supply or supply may exceed demand. Therefore, passengers' waiting time is taken as an indicator. Its definition is as follows:

$$
W_{i}=t_{2}-t_{1}
$$

In this formula, ${ }_{2}$ represents the moment the taxi passengers; ${ }^{t_{1}}$ represents the beginning of time to wait for a taxi.

\subsection{Maximum matching model when no subsidy program}

\subsubsection{Determine the decision variables}

According between taxi drivers and passengers can match each other for the decision variables, to simplify the problem, If the two can match, it is denoted as 1 ; if the two cannot match, it is denoted as 0 , there $x_{i j}= \begin{cases}0 & \text { Success Match } \\ 1 & \text { Unsuccessful match }\end{cases}$

Among them, Represents the i-th taxi drivers and $\mathrm{j}$-th passengers can match.

\subsubsection{Determine the objective function}

The objective function 1: According to taxi drivers and passengers between the maximum number of matches, there

$\max Z=\sum_{i=1}^{m} \sum_{j=1}^{n} x_{i j},(i=1,2, \cdots, m),(j=1,2, \cdots, n)$

In this formula, $\mathrm{z}$ represents the number of matches, $\mathrm{m}$ represents the number of taxis, $\mathrm{n}$ represents the number of passengers.

The objective function 2: In order to reduce passenger waiting times and increase revenue taxi drivers, In the case of a defined objective function, The distance to be considered for all matches between the minimum and the objective function, there

$\min L=\sum_{i=1}^{m} \sum_{j=1}^{n} x_{i j} d_{i j},(i=1,2, \cdots, m),(j=1,2, \cdots, n)$

Where $d_{i j}$ represents the distance between a taxi and its passengers.

\subsubsection{Determined constraints}

Constraint 1: If a passenger aboard a taxi determined, the passenger cannot take another taxi, there of vehicles, $n_{p}$ represents the total number of people. 
$\sum_{i=1}^{m} x_{i j} \leq 1,(j=1,2, \cdots, n)$

Constraint 2: If the taxi has confirmed the passenger to take, the taxi cannot take other passengers, there

$\sum_{j=1}^{n} x_{i j} \leq 1,(i=1,2, \cdots, m)$
Constraint 3: To reach the passenger seat of a taxi within 3 minutes, The distance between the cab and the passenger should be within, there

$d_{i j}<2000$

In this formula, ${ }^{d i j}$ represents the distance between the $\mathrm{cab}$ and the passenger.

In summary, there is no maximum matching model subsidy program is as follows:

$$
\begin{aligned}
& \max Z=\sum_{i=1}^{m} \sum_{j=1}^{n} x_{i j},(i=1,2, \cdots, m),(j=1,2, \cdots, n) \\
& \min L=\sum_{i=1}^{m} \sum_{j=1}^{n} x_{i j} d_{i j},(i=1,2, \cdots, m),(j=1,2, \cdots, n) \\
& \text { s.t. }\left\{\begin{array}{l}
x_{i j} \in\{0,1\} \\
d_{i j}<2000 \\
\sum_{i=1}^{n} x_{i j} \leq 1 \\
\sum_{j=1}^{m} x_{i j} \leq 1 \\
i=1,2, \cdots, m \\
j=1,2, \cdots, n
\end{array}\right.
\end{aligned}
$$

\subsection{Calculation results and analysis}

Maximum matching model of the target function has multiple, so the first model solution, should be transformed into a single multi-objective goal. Because the first target and the second target just as important, so the weighting coefficients method ${ }^{[6]}$ should be used. First setting the same weights of the two goals, and then two goals into a goal.

According to latitude and longitude of each point, can be programmed to give each taxi use MATLAB the distance between each passenger. Specific results in Table 1.

Table 1: Distance between each passenger and each taxi

\begin{tabular}{|l|l|l|l|l|l|l|l|l|l|l|l|l|l|}
\hline Distance & $\begin{array}{l}\text { 1th } \\
\text { taxi }\end{array}$ & $\begin{array}{l}\text { 2nd } \\
\text { taxi }\end{array}$ & $\begin{array}{l}\text { 3rd } \\
\text { taxi }\end{array}$ & $\begin{array}{l}\text { 4th } \\
\text { taxi }\end{array}$ & $\begin{array}{l}\text { 5th } \\
\text { taxi }\end{array}$ & $\begin{array}{l}\text { 6th } \\
\text { taxi }\end{array}$ & $\begin{array}{l}\text { 7th } \\
\text { taxi }\end{array}$ & $\begin{array}{l}\text { 8th } \\
\text { taxi }\end{array}$ & $\begin{array}{l}\text { 9th } \\
\text { taxi }\end{array}$ & $\begin{array}{l}\text { 10th } \\
\text { taxi }\end{array}$ & $\begin{array}{l}\text { 11th } \\
\text { taxi }\end{array}$ & $\begin{array}{l}\text { 12th } \\
\text { taxi }\end{array}$ & $\begin{array}{l}\text { 13th } \\
\text { taxi }\end{array}$ \\
\hline $\begin{array}{l}\text { Passengers, } \\
\text { 1th }\end{array}$ & 1.02 & 3.14 & 4.26 & 2.96 & 5.17 & 1.21 & 0.55 & 3.22 & 1.83 & 2.59 & 1.11 & 4.81 & 0.63 \\
\hline $\begin{array}{l}\text { Passengers, } \\
\text { 2nd }\end{array}$ & 5.2 & 3.08 & 1.96 & 3.26 & 1.06 & 5.01 & 5.68 & 3.01 & 4.4 & 3.63 & 5.11 & 1.41 & 5.59 \\
\hline $\begin{array}{l}\text { Passengers, } \\
\text { 3rd }\end{array}$ & 1.71 & 0.4 & 1.53 & 0.22 & 2.43 & 1.53 & 2.19 & 0.48 & 0.91 & 0.14 & 1.63 & 2.07 & 2.1 \\
\hline $\begin{array}{l}\text { Passengers, } \\
\text { 4th }\end{array}$ & 2.08 & 4.2 & 5.32 & 4.02 & 6.22 & 2.27 & 1.6 & 4.27 & 2.88 & 3.65 & 2.17 & 5.87 & 1.69 \\
\hline $\begin{array}{l}\text { Passengers, } \\
\text { 5th }\end{array}$ & 0.49 & 2.61 & 3.73 & 2.43 & 4.63 & 0.68 & 0.01 & 2.68 & 1.29 & 2.06 & 0.58 & 4.27 & 0.1 \\
\hline $\begin{array}{l}\text { Passengers, } \\
\text { 6th }\end{array}$ & 0.79 & 1.32 & 2.45 & 1.15 & 3.35 & 0.6 & 1.27 & 1.4 & 0.01 & 0.78 & 0.7 & 2.99 & 1.18 \\
\hline $\begin{array}{l}\text { Passengers, } \\
\text { 7th }\end{array}$ & 3.32 & 1.2 & 0.08 & 1.38 & 0.82 & 3.13 & 3.8 & 1.12 & 2.52 & 1.75 & 3.23 & 0.47 & 3.71 \\
\hline
\end{tabular}


Programmed to calculate taxi and passenger number of matching results, the results are shown in Table 2 .

Table 2: The number of matching of taxis and passengers

\begin{tabular}{|l|l|l|l|l|l|l|l|}
\hline $\begin{array}{c}\text { Passengers } \\
\text { Taxis }\end{array}$ & 1 & 2 & 3 & 4 & 5 & 6 & 7 \\
\hline no subsidy scheme & 7 & 5 & 10 & 11 & 13 & 9 & 3 \\
\hline
\end{tabular}

The selected data into the model, and calculated the total number of matches between taxis and passengers, analysis of the results of the program, we solved the problem of optimal driver and passenger matching.

\section{REFERENCES}

1. Wang, W. (2002). Urban public transportation system planning method and management technology $[\mathrm{M}]$. Science Press.

2. Shuai, Z. (2010). Study on allocation of taxi resources in Jiaxing city [D]. Shanghai: Shanghai Jiao Tong University.

3. Du, J., \& Han, Z. (2015). Taxi Allocation Models in the Internet+ Era [D]. Mathematical Modeling and Its Applications.

4. Guan, Y. (2010). Analysis on the reliability of Chengdu taxi floating car date [D], Chengdu: Southwest Jiaotong University.

5. Lu, J., \& Wang, W. (2004). Urban taxi quantity determination method [N]. Journal of Traffic and Transportation Engineering, 4(1).

6. Si, S., \& Sun, X. (2011). Mathematical modeling algorithm and application [M], Beijing: National Defend Industry Press. 